\title{
$\alpha$-eleostearic acid inhibits growth and induces apoptosis in breast cancer cells via HER2/HER3 signaling
}

\author{
REN-JIE ZHUO ${ }^{1 *}$, FENG WANG $^{3 *}$, XIAO-HONG ZHANG ${ }^{1}$, JIN-JIE ZHANG ${ }^{2}$, \\ JIN XU ${ }^{1}$, WEI DONG ${ }^{1}$ and ZU-QUAN ZOU ${ }^{1}$ \\ ${ }^{1}$ Medical School and ${ }^{2}$ Maritime Faculty, Ningbo University, Ningbo, Zhejiang 315211; \\ ${ }^{3}$ Clinical Laboratory, Lihuili Hospital, Ningbo, P.R. China
}

Received August 2, 2013; Accepted January 6, 2014

DOI: $10.3892 / \mathrm{mmr} .2014 .1892$

\begin{abstract}
ESA) has been shown to possess antitumor activity in cancer cells. However, the underlying mechanism(s) remain largely unknown. The present study was designed to investigate the antitumor effect of $\alpha$-ESA in breast cancer cells showing different expression levels of the human epidermal growth factor receptor 2 (HER2). $\alpha$-ESA inhibited cell growth and induced apoptosis in the SKBR3 and T47D breast cancer cell lines. The mechanism by which cell growth was inhibited involved $\mathrm{G}_{0} / \mathrm{G}_{1}$ and $\mathrm{G}_{2} / \mathrm{M}$ cell cycle phase arrest. The MTT assay showed that SKBR3 cells are more sensitive to $\alpha$-ESA compared to T47D cells. Western blot analysis revealed that $\alpha$-ESA treatment not only reduced HER2/HER3 protein expression, but also increased the level of phosphorylated phosphatase and tensin homolog protein (PTEN), which led to decreased levels of phosphorylated Akt. Inactive Akt further reduced phosphorylation of glycogen synthase kinase-3 $\beta$ (GSK-3 $\beta$ ) and B-cell lymphoma 2 (Bcl-2)-associated death promoter (BAD) proteins. Furthermore, the level of the anti-apoptotic protein Bcl-2 was found to be reduced following $\alpha$-ESA treatment. Notably, nuclear factor $\kappa \mathrm{B}(\mathrm{NF}-\kappa \mathrm{B})$ was activated by $\alpha$-ESA treatment. Data of the present study showed that the antitumor activity of $\alpha$-ESA is at least partly mediated by reduction of the HER2/HER3 heterodimer protein level, activation of the $\mathrm{Akt} / \mathrm{BAD} / \mathrm{Bcl}-2$ apoptotic pathway and inhibition of the Akt/GSK-3 $\beta$ survival pathway in the two breast cancer cell lines investigated in this study. Therefore, $\alpha$-ESA may be considered a beneficial dietary factor for the prevention and treatment of invasive breast cancer in cells overexpressing HER2.
\end{abstract}

Correspondence to: Professor Zu-Quan Zou, Medical School, Ningbo University, 818 Fenghua Road, Ningbo, Zhejiang 315211, P.R. China

E-mail: zouzuquan@nbu.edu.cn

*Contributed equally

Key words: $\alpha$-ESA, HER 2, HER 3, breast cancer

\section{Introduction}

Breast cancer is the most common malignancy among women and is the leading cause of female cancer mortality worldwide. Current therapies only delay its progression, while the survival rate of breast cancer patients remains low due to inevitable recurrence and the absence of efficient systemic therapies (1). Numerous types of cancer, including breast cancer, are associated with the human epidermal growth factor receptor (HER) family. This family consists of four highly homologous members, epidermal growth factor (EGFR), HER2, HER3 and HER4. HER 2 is overexpressed in $25-30 \%$ of invasive breast cancers and strongly correlates with poor prognosis and resistance to certain chemotherapeutic agents (2). HER3 can form an active heterodimer with HER2, characterized as the most potent signaling complex of the HER family, triggering the downstream signaling pathway of phosphatidylinositol 3-kinase $(\mathrm{PI} 3 \mathrm{~K}) / \mathrm{Akt}$, which controls cell proliferation, survival and apoptosis $(3,4)$. In the last two decades, HER 2 has been highlighted as a promising therapeutic target, prompting the development of highly effective antitumor drugs, such as trastuzumab, a monoclonal antibody targeting HER2, and lapatinib, a dual tyrosine kinase inhibitor (TKI) targeting HER2- and EGFR-related pathways $(5,6)$. However, these TKIs show limited activity in HER2-driven breast cancers. This may be due to TKI-induced compensatory upregulation of HER3 and its phosphorylation (7). The development of specific small-molecule inhibitors against HER3 is challenging, since HER3 lacks innate tyrosine kinase activity. Therefore, blocking HER2/HER3 expression and the downstream signal transduction pathway using nutritional intervention may be a more efficient therapeutic strategy in breast cancer treatment.

The extract of Momordica charantia, also known as bitter melon, was previously reported to exert antitumor effects in breast cancer in vitro and in vivo (8). Of particular interest is the fact that up to $50 \%$ of bitter melon seed oil consists of eleostearic acid ( $\alpha$-ESA), a conjugated trienoic fatty acid. There is increasing evidence that $\alpha$-ESA exhibits antitumor activity in breast cancer cells. For instance, $\alpha$-ESA blocked cell proliferation and induced apoptosis in breast cancer cells, and addition of $\alpha$-tocopherol affected oxidative stress and apoptosis, suggesting that $\alpha$-ESA-induced apoptosis is associated with lipid peroxidation (9). In addition, $\alpha$-ESA showed 
antiproliferative activity in breast cancer cells via activation of PPAR $\gamma$ and inhibition of ERK 1/2 phosphorylation (10). Furthermore, it was recently reported that $\alpha$-ESA exerts growth inhibition and apoptotic effects through the promotion of cell cycle arrest and upregulation of apoptosis-related proteins in breast cancer cells (11). However, whether membrane receptors HER2/HER3 and the related downstream signaling pathway are involved in the antitumor effect of $\alpha$-ESA in breast cancer cells remains to be addressed.

In this study, two breast cancer cell lines, SKBR3 overexpressing HER2, and T47D, showing relatively lower expression levels of HER2, were used to investigate the antitumor effects of $\alpha$-ESA. Our results demonstrated that $\alpha$-ESA markedly inhibits cell growth and induces apoptosis in the two cell lines, and that the antitumor activity of $\alpha$-ESA involves, at least in part, inhibition of HER2/HER3 expression and of the downstream signal transduction pathway.

\section{Materials and methods}

Cells and reagents. Human breast cancer cell lines SKBR3 and T47D were obtained from the Cell Bank of Type Culture Collection of the Chinese Academy of Science. The cells were cultured at $37^{\circ} \mathrm{C}$ under $5 \% \mathrm{CO}_{2}$ in RPMI-160 and Dulbecco's modified Eagle's medium (DMEM), respectively, both supplemented with $10 \%$ fetal bovine serum (FBS). The primary antibodies targeting HER2, HER3, phospho-Akt (Ser473), phospho-glycogen synthase kinase-3 $\beta$ (GSK-3 $\beta$ ) (Ser9), phospho-phosphatase and tensin homolog (PTEN) (S380), nuclear factor $\kappa \mathrm{B}(\mathrm{NF}-\kappa \mathrm{B})$, phospho-NF- $\kappa \mathrm{B}$ (S536), B-cell lymphoma 2 (Bcl-2) and phospho-Bcl-2-associated death promoter (BAD) (S136) were from Cell Signaling Technology (Beverly, MA, USA).

Cell viability (MTT) assay. SKBR3 and T47D cells were seeded in 96 -well plates at a density of $7 \times 10^{3}$ cells/well. After overnight incubation to allow cell attachment, the cells were treated with $\alpha$-ESA in serum-free medium for 24,48 and $72 \mathrm{~h}$. For the MTT assay, $20 \mu \mathrm{l} \mathrm{MTT} \mathrm{(at} 5 \mathrm{mg} / \mathrm{ml}$ ) was added to each well and the mixture was then incubated for $4 \mathrm{~h}$ in a $37^{\circ} \mathrm{C}$ incubator. The mixture in each well was then removed, and $100 \mu \mathrm{l}$ dimethyl sulfoxide was added into each well. The absorbance was read at $450 \mathrm{~nm}$ with a microplate reader (Bio-Rad, Hercules, CA, USA). Measurements were performed in triplicate.

Cell cycle assay. Cells (2x10 $/$ well) were seeded into 6-well plates and incubated in culture medium for $24 \mathrm{~h}$. The cells were treated with $\alpha$-ESA $(40 \mu \mathrm{M})$ for $48 \mathrm{~h}$, and then harvested. After washing with phosphate-buffered saline (PBS), the cells were fixed with ice-cold $70 \%$ ethanol at $4^{\circ} \mathrm{C}$ for $24 \mathrm{~h}$. Cell staining was performed by incubation with cell cycle reagents from Beckman Coulter, Inc. (Miami, FL, USA) for $30 \mathrm{~min}$ at room temperature in the dark. Cell cycle distribution was then analyzed by flow cytometry on a FACSCalibur cytometer and data were analyzed with the CellQuest Pro software (both from BD Biosciences, San Jose, CA, USA).

DAPI staining. Cells (4x105/well) were plated into 6-well plates with slide and allowed to adhere overnight. The cells were treated with $\alpha$-ESA $(40 \mu \mathrm{M})$ for $48 \mathrm{~h}$ and washed with PBS three times. They were then fixed with $4 \%$ paraformaldehyde (SigmaAldrich, St. Louis, MO, USA) for $10 \mathrm{~min}$ at room temperature and incubated with $10 \mu \mathrm{g} / \mathrm{ml}$ of 4,6-diamidino-2-phenylindole (DAPI) for $5 \mathrm{~min}$ at room temperature in the dark. Slides were washed three times with PBS and analyzed under a confocal laser scanning microscope. Digital images were acquired with FluoView software (Olympus, Melville, NY, USA).

Western blotting. Cell extracts were prepared in lysis buffer (20 mM Tris-HCl, pH 7.6, 1 mM EDTA, $140 \mathrm{mM} \mathrm{NaCl}$, $1 \%$ Nonidet $\mathrm{P}-40,1 \%$ aprotinin, $1 \mathrm{mM}$ phenylmethylsulfonyluoride, and $1 \mathrm{mM}$ sodium vanadate). Protein concentration of the sample was determined by the bicinchoninic acid (BCA) protein assay. Equal amounts of protein were subjected to $10 \%$ SDS-PAGE electrophoresis and the gel was transferred to a nitrocellulose membrane. The membrane was blocked with $5 \%$ milk and incubated with primary antibodies at $4^{\circ} \mathrm{C}$ overnight. The membrane was then incubated with horseradish peroxidase-conjugated rabbit secondary antibodies for $1 \mathrm{~h}$ at room temperature. Detection of the resulting complexes was performed with enhanced chemiluminescence (ECL).

\section{Results}

Sensitivity of human breast cancer cells to $\alpha$-ESA. To investigate the sensitivity of human breast cancer cells to $\alpha$-ESA, SKBR3 and T47D cells were treated with $\alpha$-ESA for 24,48 and $72 \mathrm{~h}$ in serum-free medium. As shown in Fig. 1, exposure to $\alpha$-ESA led to dose- and time-dependent growth inhibition in the two cell lines. SKBR3 cells were more sensitive to $\alpha$-ESA compared to T47D cells. Treatment with $80 \mu \mathrm{M} \alpha$-ESA for 24,48 and $72 \mathrm{~h}$ induced over 60,66 and $81 \%$ reduction in SKBR3 cell viability, and $\sim 38,53$ and $60 \%$ reduction in T47D cell viability, respectively.

$\alpha$-ESA induces cell cycle arrest. We performed flow cytometry analysis to investigate the ability of $\alpha$-ESA to alter the cell cycle. As shown in Fig. 2, the incubation of SKBR3 and T47D cells with $\alpha$-ESA $(40 \mu \mathrm{M})$ resulted in $\mathrm{G}_{0} / \mathrm{G}_{1}$ and $\mathrm{G}_{2} / \mathrm{M}$ cell cycle arrest. The percentage of SKBR3 cells at the $\mathrm{G}_{0} / \mathrm{G}_{1}$ and $\mathrm{G}_{2} / \mathrm{M}$ phases increased from 62.3 and $4.02 \%$ to 65.9 and $9.2 \%$, respectively. In addition, the percentage of T47D cells at the $\mathrm{G}_{0} / \mathrm{G}_{1}$ and $\mathrm{G}_{2} / \mathrm{M}$ phases increased from 31.21 and $8.6 \%$ to 37.8 and $14.25 \%$, respectively.

$\alpha$-ESA induces apoptosis in human breast cancer cells. To determine whether decreased survival induced by $\alpha$-ESA was associated with cell apoptosis, SKBR3 and T47D cells were treated with $40 \mu \mathrm{M} \alpha$-ESA for $48 \mathrm{~h}$, and stained with DAPI. As compared to the control, morphological changes characteristic of apoptosis (increased nuclear condensation and fragmentation) were noted in $\alpha$-ESA-treated cells (Fig. 3).

$\alpha$-ESA inhibits HER 2 and HER 3 expression, and downstream survival signaling. In order to assess the mechanism by which $\alpha$-ESA induces growth inhibition and cell apoptosis in breast cancer cells, western blot analysis was used to examine the expression of the HER2/HER3 signaling pathway proteins in $\alpha$-ESA-treated cells. As shown in Fig. 4, $\alpha$-ESA treatment 

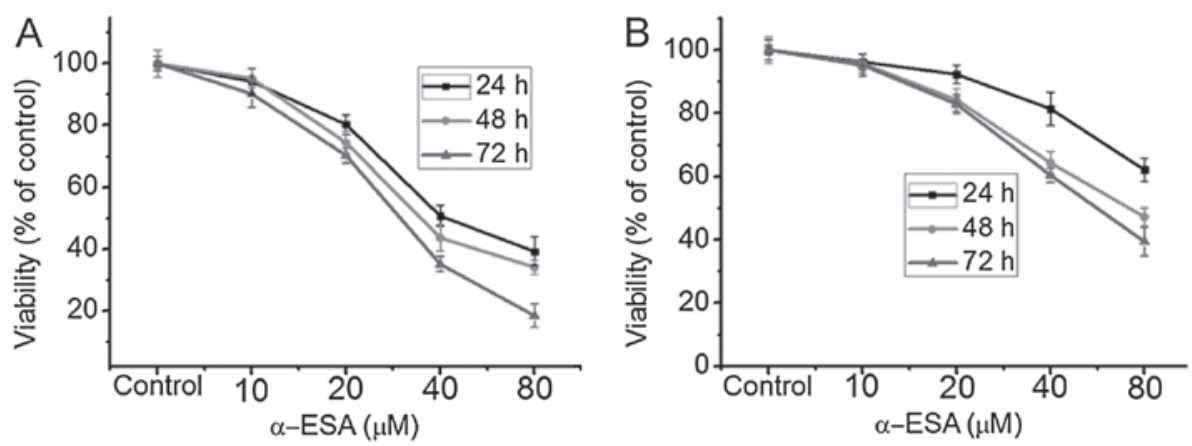

Figure 1. Effects of $\alpha$-eleostearic acid ( $\alpha$-ESA) on the viability of (A) SKBR3 and (B) T47D cells. Cells (7x10 3 cells/well) were seeded in 96-well plates and cultured in medium supplemented with $10 \%$ fetal bovine serum (FBS) for $24 \mathrm{~h}$. The cells were treated with increasing concentrations $(0-80 \mu \mathrm{M})$ of $\alpha$-ESA for 24,48 and $72 \mathrm{~h}$ in serum-free medium. Cell viability was determined with the MTT assay. The experiments were repeated three times and gave similar results.
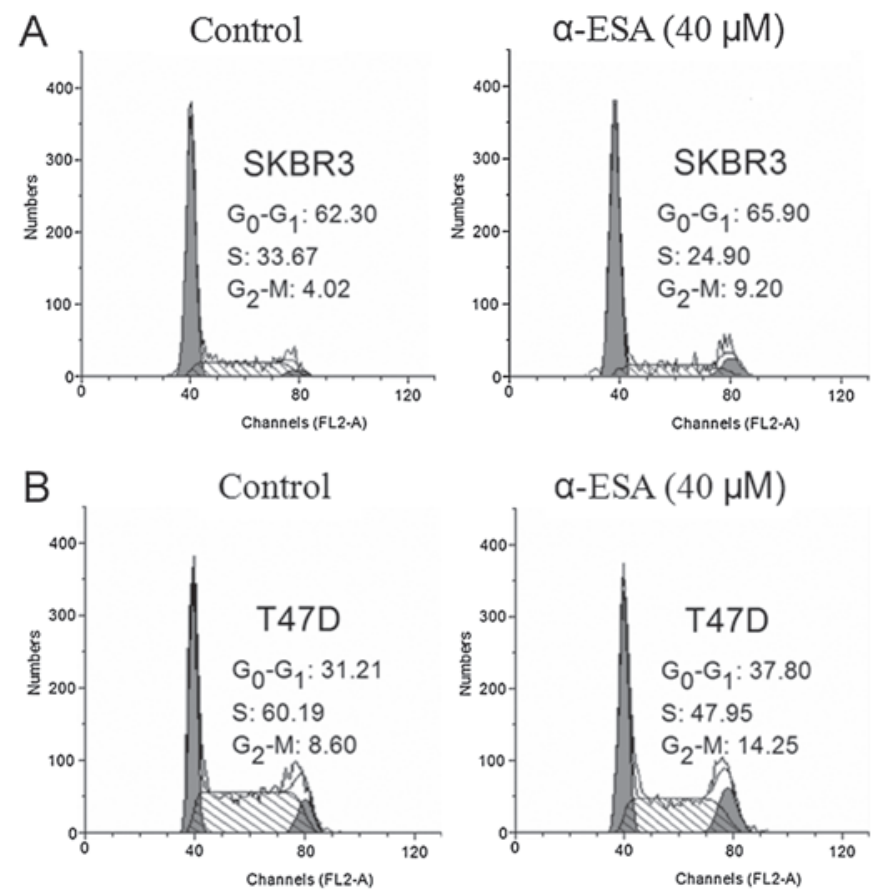

Figure 2. $\alpha$-eleostearic acid ( $\alpha$-ESA) treatment results in arrest at the $\mathrm{G}_{0} / \mathrm{G}_{1}$ and $\mathrm{G}_{2} / \mathrm{M}$ cell cycle phase in (A) SKBR3 and (B) T47D cells. Cells $\left(2 \times 10^{5}\right.$ cells/well) were seeded in 6 -well plates and cultured in medium supplemented with $10 \%$ fetal bovine serum (FBS) for $24 \mathrm{~h}$. The cells were treated with $\alpha$-ESA in serum-free medium for $48 \mathrm{~h}$ and analyzed by flow cytometry. Results are represented as percentage of the cell population detected at the $\mathrm{G}_{0} / \mathrm{G}_{1}, \mathrm{~S}$ and $\mathrm{G}_{2} / \mathrm{M}$ phases of the cell cycle.

decreased the HER2 and HER3 protein levels in SKBR3 and T47D cells, and this effect was dose-dependent. To determine whether the $\alpha$-ESA-induced decrease of HER2/ HER3 further inhibits the related downstream signaling pathway, we examined phosphorylation levels of Akt and GSK- $3 \beta$ in cells treated with $\alpha$-ESA. As shown in Fig. 4, $\alpha$-ESA treatment decreased serum-induced Akt and GSK-3 $\beta$ phosphorylation in the two cell lines, with a more prominent decrease observed in SKBR3 cells compared to T47D cells. To determine whether PTEN activation is involved in the $\alpha$-ESA-mediated decrease in Akt phosphorylation, phosporylation of PTEN was examined in cells treated with $\alpha$-ESA. As shown in Fig. 4, phosphorylation of PTEN was markedly increased in the two breast cancer cell lines treated with
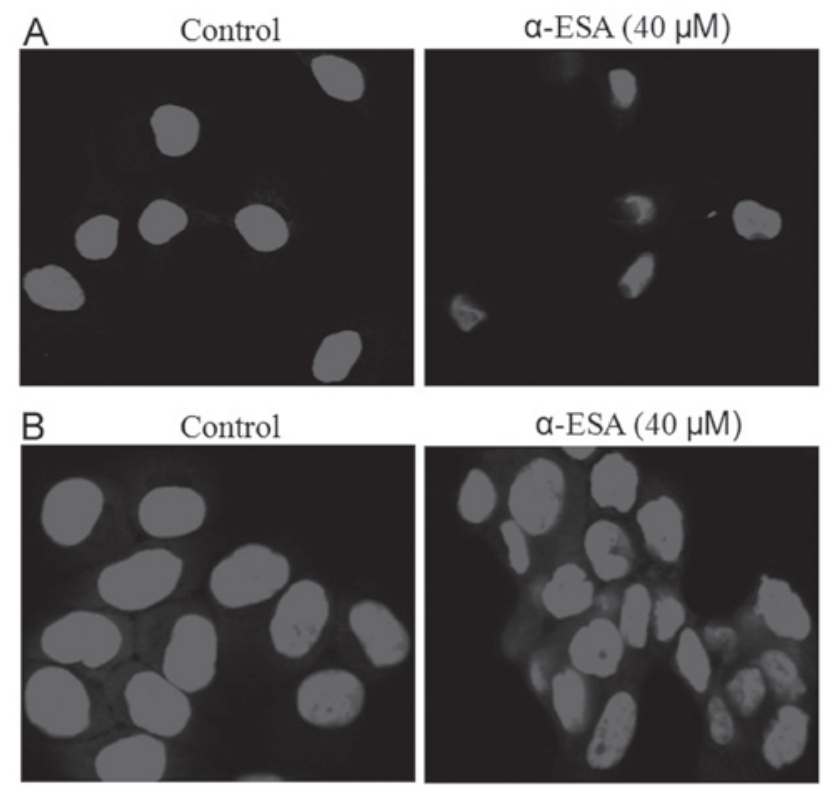

Figure 3. Effects of $\alpha$-eleostearic acid ( $\alpha$-ESA) on cell apoptosis of (A) SKBR3 and (B) T47D cells. Cells $\left(4 \times 10^{5}\right.$ cells/well) were plated into 6 -well plates with the slides and were allowed to adhere overnight. The cells were treated with $\alpha$-ESA in serum-free medium for $48 \mathrm{~h}$ and stained with 4,6-diamidino-2-phenylindole (DAPI). The cells were then observed and photographed with an oil lens at x630 magnification.

$\alpha$-ESA for $48 \mathrm{~h}$. In addition, there is evidence that activated $\mathrm{NF}-\kappa \mathrm{B}$ is involved in oncogenesis (12). To verify whether the antitumor effect of $\alpha$-ESA is mediated by NF- $\kappa B$, we examined the protein level of NF- $\kappa \mathrm{B}$ and its phoshorylated form. Of note, NF- $\kappa B$ expression was slightly decreased, but the level of its phosphorylated form was markedly increased upon $\alpha$-ESA treatment in both cell lines.

$\alpha$-ESA activates the BAD-dependent apoptotic pathway. The anti-apoptotic effect mediated by the PI3K/Akt pathway involves Akt phosphorylation of BAD. BAD phosphorylation at Ser 36 promotes its binding to the 14-3-3 protein isoforms instead of Bcl-2 or Bcl-xL. Released anti-apoptotic proteins may be associated with Bax to promote cell survival (13). To determine whether $\alpha$-ESA-induced apoptosis is mediated by BAD phosphorylation by Akt, BAD phosphorylation (Ser136) was semi-quantitatively assessed following $\alpha$-ESA treatment 


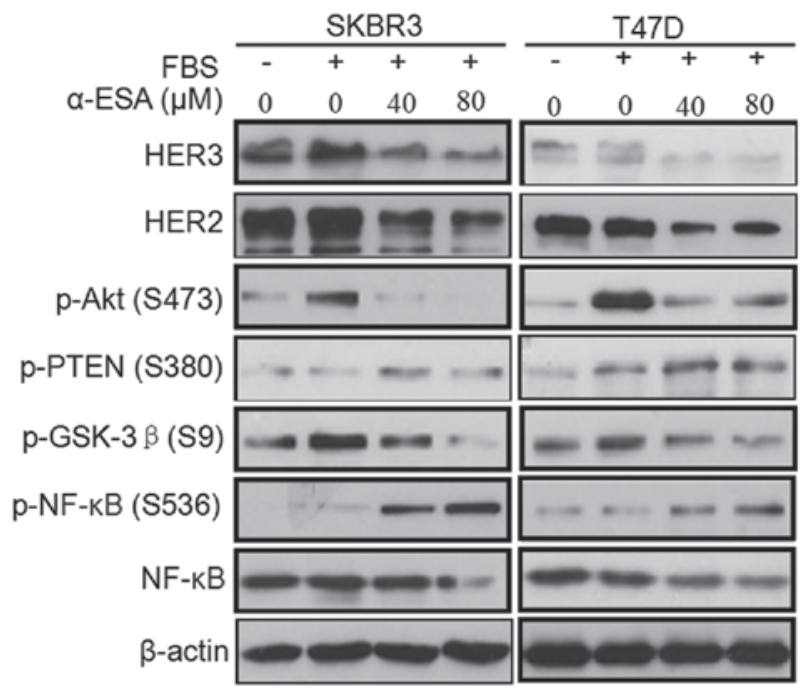

Figure 4. $\alpha$-eleostearic acid ( $\alpha$-ESA) reduces the expression of human epidermal growth factor receptor 2 (HER2) and HER3 and inhibits downstream signaling in SKBR3 and T47D cells. The cells were treated with $\alpha$-ESA in serum-free medium for $48 \mathrm{~h}$ and stimulated with $10 \%$ fetal bovine serum (FBS) for $1 \mathrm{~h}$. Changes in HER2, HER3, p-Akt, p-phosphatase and

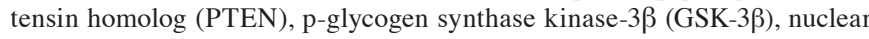
factor $\kappa \mathrm{B}(\mathrm{NF}-\kappa \mathrm{B})$ and $\mathrm{p}-\mathrm{NF}-\kappa \mathrm{B}$ were examined by western blot analysis, with $\beta$-actin as the loading control.

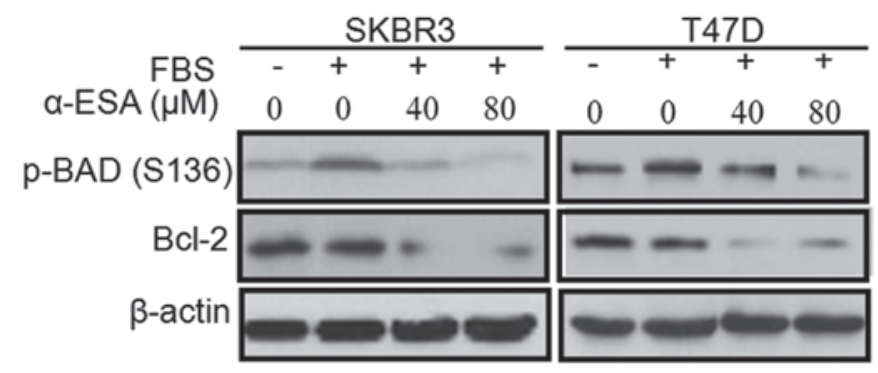

Figure 5. Effects of $\alpha$-eleostearic acid ( $\alpha$-ESA) on B-cell lymphoma 2 (Bcl-2) and $\mathrm{p}-\mathrm{Bcl}-2$-associated death promoter (BAD) in SKBR3 and T47D cells. The cells were treated with $\alpha$-ESA in serum-free medium for $48 \mathrm{~h}$ and then stimulated with $10 \%$ fetal bovine serum (FBS) for $1 \mathrm{~h}$. Changes in p-BAD and Bcl-2 were examined by western blot analysis, with $\beta$-actin as the loading control.

with western blot analysis. As shown in Fig. 5, $\alpha$-ESA treatment reduced serum-induced phosphorylation of BAD at Ser 136 in the two cell lines. In addition, Bcl-2 is a known antiapoptotic protein in the pathway of mitochondrial apoptosis, and our results showed that $\mathrm{Bcl}-2$ expression was markedly decreased upon $\alpha$-ESA treatment.

\section{Discussion}

Breast cancer currently remains the leading cause of cancer death in women worldwide; in 2004, it accounted for an estimated 519,000 deaths (14). Despite application of systemic therapeutic treatment such as chemotherapy, radiotherapy and targeted therapy in late-stage breast cancer cases, the 5 -year survival rate remains low, owing to considerable toxicity side-effects or drug resistance (15). Nevertheless, preclinical and clinical findings recently revealed that dietary factors can play crucial roles in cancer prevention and treatment $(16,17)$.

In the present study, $\alpha$-ESA, a conjugated trienoic fatty acid found in considerable amounts in bitter melon seed oil, directly reduced the viability of SKBR3 and T47D breast cancer cells in a time- and dose-dependent manner (Fig. 1). The mechanism by which $\alpha$-ESA exerts this inhibitory effect involves the induction of $\mathrm{G}_{0} / \mathrm{G}_{1}$ and $\mathrm{G}_{2} / \mathrm{M}$ cell cycle phase arrest. Of note, exposure to $\alpha$-ESA $(80 \mu \mathrm{M})$ for $24 \mathrm{~h}$ induced $\sim 60 \%$ growth inhibition in SKBR3 cells. However, treatment with $80 \mu \mathrm{M}$ docosahexaenoic acid (DHA) for $24 \mathrm{~h}$ only slightly inhibited the proliferation of SKBR3 cells (unpublished data). A previous study demonstrated that $\alpha$-ESA is quickly converted to conjugated linoleic acid with a double bond cleavage (18), and it may be that $\alpha$-ESA exerts its more rapid antitumor activity via double bond cleavage-mediated oxidative stress. Previous studies have shown that bitter melon extract and $\alpha$-ESA induced growth inhibition and cell apoptosis in breast and prostate cancer cells $(8,9,11,19)$. The main mechanism proposed for the $\alpha$-ESA antitumor effect in these studies was oxidative stress $(9,11)$. However, HER family members are invovled in the development and progression of cancer. Additionally, overexpression of HER2 is evident in invasive breast cancers and serves as a frequent target of mammary oncogenesis (20). In addition, HER3 is required for HER2-induced preneoplastic changes in the breast epithelium and tumor formation, and drives therapeutic resistance to HER2 inhibitors (21). In this context, the aim of the present study was to examine the effect of $\alpha$-ESA on the membrane receptor heterodimer HER2/HER3 and the related downstream signaling pathways.

We have demonstrated that $\alpha$-ESA reduces, not only the HER2 protein level, but also HER3 expression in two breast cancer cell lines showing different levels of HER2 expression (Fig. 4). Besides $\alpha$-ESA, HER2/HER3 expression is also modulated by other $n-3$ polyunsaturated fatty acids (PUFAs) such as DHA and eicosapntemacnioc acid (EPA). We previously found a low ratio of n-6/n-3 PUFAs in breast tumor tissues of fat- 1 transgenic rats that ubiquitously convert $n-6$ to n-3 PUFAs, accompanied by reduced HER2/HER3 expression and restricted tumor growth (unpublished data). In addition, we (unpublished data) and Menendez et al (22) found that DHA decreases HER2 expression in breast cancer cells. Results of the present study suggest that clinical use of $\alpha$-ESA, unlike HER2 inhibitors, may circumvent drug resistance that is so vital in breast cancer prevention and treatment, owing to the mechanism of action of this molecule, which involves inhibition of HER2/HER3-related pathways.

PI3K/Akt is an important HER2/HER3 downstream signaling pathway that negatively regulates cell growth and apoptosis. The tumor suppressor protein PTEN opposes the action of PI3K by dephosphorylating the signaling lipid molecule phosphatidylinositol (3,4,5)-trisphosphate (23). Our findings showed that $\alpha$-ESA treatment blocks serum-stimulated phosphorylation of Akt in the two breast cancer cell lines examined. In addition, we found that PTEN is activated via phosphorylation by $\alpha$-ESA. Overall, these results suggest that decreased HER2/HER3 expression along with activation of PTEN upon $\alpha$-ESA treatment may lead to decreased Akt phosphorylation. In line with our results, $\alpha$-ESA-induced 
inhibition of Akt phosphorylation in HeLa cells was reported by Eom et al (24). GSK-3 $\beta$ acts downstream of Akt to mediate epidermal growth factor, insulin and Wnt signals to various downstream pathways regulating processes such as glycogen metabolism, cell proliferation and differentiation. We showed that $\alpha$-ESA reduced GSK- $3 \beta$ phosphorylation, which coincided with decreased Akt phosphorylation. This suggests that the PI3K/Akt/GSK-3 $\beta$ pathway is involved in the antitumor activity of $\alpha$-ESA. In addition, Eom et al (24) found that $\alpha$-ESA induced autophage-dependent apoptosis through targeting the $\mathrm{Akt} / \mathrm{mammalian}$ targets of rapamycin (mTOR) pathway. Members of the NF- $\mathrm{B}$ family of transcription factors are involved in the regulation of a wide spectrum of biological responses. NF- $\kappa \mathrm{B}$ activation is dependent itself on various signaling pathways, such as the Ras/ mitogen-activated protein kinase (MAPK) and PI3K/Akt. Therefore, we hypothesized that $\alpha$-ESA-mediated inhibition of Akt phosphorylation is involved in the inhibition of NF- $\kappa \mathrm{B}$. Notably, in the cells treated with $\alpha$-ESA, expression of $N F-\kappa B$ was slightly decreased, but its phosphorylation was markedly increased, suggesting that the PI3K/Akt pathway may not be involved in regulating $\mathrm{NF}-\kappa \mathrm{B}$ activation, although activated $\mathrm{NF}-\kappa \mathrm{B}$ plays a vital role in promoting oncogenesis. There is evidence that oxidized lipoproteins activate $N F-\kappa B$ and induce cell apoptosis (25). Therefore, the antitumor activity of $\alpha$-ESA may be associated with oxidative stress via NF- $\mathrm{B}$ activation, and future studies are needed to elucidate this hypothesis.

Besides cell growth inhibition, $\alpha$-ESA also induced cell apoptosis, as evidenced by an increase in nuclear condensation and fragmentation in the two breast cancer cell lines using DAPI staining. Additional recent studies have indicated that apoptosis induction by $\alpha$-ESA occurs in breast cancer, cervix carcinoma and leukemia (9-11,24). Unphosphorylated BAD binds to the anti-apoptotic protein Bcl-2 to exert its pro-apoptotic effect. Akt exerts survival signals by phosphorylating BAD, which blocks BAD-induced apoptosis (13). Our results showed that $\alpha$-ESA reduced BAD phosphorylation at Ser 136, suggesting that Akt-mediated BAD phosphorylation is involved in $\alpha$-ESA-induced apoptosis (Fig. 5). Moreover, $\alpha$-ESA affected the expression of the anti-apoptotic protein Bcl-2. In line with our results, a study by Moon et al reported $\alpha$-ESA-induced decrease in Bcl-2 levels in MCF7 breast cancer cells (10). Overall, these data suggest that a decreased $\mathrm{Bcl}-2$ expression and increased BAD binding to Bcl-2 mediate $\alpha$-ESA-induced apoptosis.

In summary, the current study provided promising preclinical evidence on the molecular mechanisms by which $\alpha$-ESA may regulate the malignant behavior of breast cancer cells. These results may be helpful in the development of clinical interventions that would use $\alpha$-ESA for the prevention and treatment of breast cancer, as well as for nutritional support of cancer patients, allowing them to overcome weight loss and regulate their immune system.

\section{Acknowledgements}

This study was partly sponsored by the K.C.Wong Magna Fund in Ningbo University and supported by grants from the National Science Foundation of China (nos. 81102121,
81172660 and 31201284), the Scientific Innovation Team Project (no. 2011B82014) and the Science Foundation (no. 2010A610057) of Ningbo. We are also grateful to Jing Yang for cell cultures and Shi-Yong Chen for useful discussions.

\section{References}

1. Perou CM, Sørlie T, Eisen MB, van de Rijn M, Jeffrey SS, Rees CA, Pollack JR, Ross DT, Johnsen H, Akslen LA, et al: Molecular portraits of human breast tumours. Nature 406: 747-752, 2000.

2. Yu D and Hung MC: Role of erbB2 in breast cancer chemosensitivity. Bioessays 22: 673-680, 2000.

3. Hynes NE and Lane HA: ERBB receptors and cancer: the complexity of targeted inhibitors. Nat Rev Cancer 5: 341-354, 2005.

4. Olayioye MA, Neve RM, Lane HA and Hynes NE: The ErbB signaling network: receptor heterodimerization in development and cancer. EMBO J 19: 3159-3167, 2000

5. Konecny GE, Pegram MD, Venkatesan N, Finn R, Yang G, Rahmeh M, Untch M, Rusnak DW, Spehar G, Mullin RJ, et al: Activity of the dual kinase inhibitor lapatinib (GW572016) against HER-2-overexpressing and trastuzumab-treated breast cancer cells. Cancer Res 66: 1630-1639, 2006.

6. Smith BL, Chin D, Maltzman W, Crosby K, Hortobagyi GV and Bacus SS: The efficacy of Herceptin therapies is influenced by the expression of other erbB receptors, their ligands and the activation of downstream signalling proteins. Br J Cancer 91: 1190-1194, 2004

7. Sergina NV, Rausch M, Wang D, Blair J, Hann B, Shokat KM and Moasser MM: Escape from HER-family tyrosine kinase inhibitor therapy by the kinase-inactive HER3. Nature 445: 437-441, 2007.

8. Ray RB, Raychoudhuri A, Steele R and Nerurkar P: Bitter melon (Momordica charantia) extract inhibits breast cancer cell proliferation by modulating cell cycle regulatory genes and promotes apoptosis. Cancer Res 70: 1925-1931, 2010.

9. Grossmann ME, Mizuno NK, Dammen ML, Schuster T, Ray A and Cleary MP: Eleostearic acid inhibits breast cancer proliferation by means of an oxidation-dependent mechanism. Cancer Prev Res (Phila) 2: 879-886, 2009.

10. Moon HS, Guo DD, Lee HG, Choi YJ, Kang JS, Jo K, Eom JM, Yun $\mathrm{CH}$ and Cho CS: Alpha-eleostearic acid suppresses proliferation of MCF-7 breast cancer cells via activation of PPAR $\gamma$ and inhibition of ERK 1/2. Cancer Sci 101: 396-402, 2010.

11. Zhang T, Gao Y,Mao Y,Zhang Q,Lin C,Lin P,Zhang J and Wang X: Growth inhibition and apoptotic effect of alpha-eleostearic acid on human breast cancer cells. J Nat Med 66: 77-84, 2012.

12. Dolcet X, Llobet D, Pallares J and Matias-Guiu X: NF- $\kappa$ B in development and progression of human cancer. Virchows Arch 446: 475-482, 2005.

13. Datta SR, Dudek H, Tao X, Masters S, Fu H, Gotoh Y and Greenberg ME: Akt phosphorylation of BAD couples survival signals to the cell-intrinsic death machinery. Cell 91: 231-241, 1997.

14. Dhillon S: Everolimus in combination with exemestane: a review of its use in the treatment of patients with postmenopausal hormone receptor-positive, HER2-negative advanced breast cancer. Drugs 73: 475-485, 2013.

15. Jemal A, Siegel R, Ward E, Hao Y, Xu J, Murray T and Thun MJ: Cancer statistics, 2008. CA Cancer J Clin 58: 71-96, 2008.

16. Brennan SF, Cantwell MM, Cardwell CR, Velentzis LS and Woodside JV: Dietary patterns and breast cancer risk: a systematic review and meta-analysis. Am J Clin Nutr 91: 1294-1302, 2010.

17. Montales MT, Rahal OM, Kang J, Rogers TJ, Prior RL, Wu X and Simmen RC: Repression of mammosphere formation of human breast cancer cells by soy isoflavone genistein and blueberry polyphenolic acids suggests diet-mediated targeting of cancer stem-like/progenitor cells. Carcinogenesis 33: 652-660, 2012.

18. Tsuzuki T, Tokuyama Y, Igarashi M, Nakagawa K, Ohsaki Y, Komai M and Miyazawa T: $\alpha$-eleostearic acid (9Z11E13E-18:3) is quickly converted to conjugated linoleic acid (9Z11E-18: ) in rats. J Nutr 134: 2634-2639, 2004.

19. Ru P, Steele R, Nerurkar PV, Phillips N and Ray RB: Bitter melon extract impairs prostate cancer cell-cycle progression and delays prostatic intraepithelial neoplasia in TRAMP model. Cancer Prev Res 4: 2122-2130, 2011. 
20. Nahta R, Yu D, Hung MC, Hortobagyi GN and Esteva FJ: Mechanisms of disease: understanding resistance to HER2-targeted therapy in human breast cancer. Nat Clin Pract Oncol 3: 269-280, 2006.

21. Vaught DB, Stanford JC, Young C, Hicks DJ, Wheeler F, Rinehart C, Sánchez V, Koland J, Muller WJ, Arteaga CL and Cook RS: HER3 is required for HER2-induced preneoplastic changes to the breast epithelium and tumor formation. Cancer Res 72: 2672-2682, 2012.

22. Menendez JA, Vazquez-Martin A, Ropero S, Colomer R, Lupu R and Trueta J: HER2 (erbB-2)-targeted effects of the omega-3 polyunsaturated. Fatty acid $\alpha$-linolenic acid (ALA; $18: 3 n-3$ ) in breast cancer cells: the 'fat features' of the 'Mediterranean diet' as an 'anti-HER2 cocktail'. Clin Trans Oncol 8: 812-820, 2006.
23. Carracedo A and Pandolfi PP: The PTEN-PI3K pathway: of feedbacks and cross-talks. Oncogene 27: 5527-5541, 2008.

24. Eom JM, Seo MJ, Baek JY, Chu H, Han SH, Min TS, Cho CS and Yun $\mathrm{CH}$ : Alpha-eleostearic acid induces autophagy-dependent cell death through targeting AKT/mTOR and ERK1/2 signal together with the generation of reactive oxygen species. Biochem Biophys Res Commun 391: 903-908, 2010.

25. Draczynska-Lusiak B, Chen YM and Sun AY: Oxidized lipoproteins activate NF-kappaB binding activity and apoptosis in PC12 cells. Neuroreport 9: 527-532, 1998. 